\title{
THE CONTENT OF FREE AND BOUND INOSITOL IN HUMAN AND COW'S MILK
}

\author{
Katsunori Ogasa, Morio Kuboyama, Isao Kiyosawa, \\ Takashi SuzuKI, and Mayumi ITOH ${ }^{1}$ \\ Central Research Laboratory, Morinaga Milk Industry Co., Ltd. \\ (Received October 7, 1974)
}

\begin{abstract}
Summary The gaschromatographic method was used for the quantitative analyses of inositol in milk. The content of inositol in human and cow's milk at the different lactation periods was determined. The content of total myoinositol in human milk was $32.7 \pm 15.2 \mathrm{mg} / 100 \mathrm{ml}$ in colostrum, $17.8 \pm 1.9 \mathrm{mg} / 100 \mathrm{ml}$ in transitional milk, and $14.9 \pm 3.1 \mathrm{mg} /$ $100 \mathrm{ml}$ in mature milk. In cow's milk, it was $10.6 \pm 1.0,7.0 \pm 1.1$, and $4.1 \pm 1.0 \mathrm{mg} / 100 \mathrm{ml}$, respectively. These values were very similar to those obtained by the microbiological method. The presence of lipidbound myoinositol in both kinds of milk was confirmed and the content was $0.22 \pm 0.09 \mathrm{mg} / 100 \mathrm{ml}$ in human milk and $0.36 \pm 0.10 \mathrm{mg} /$ $100 \mathrm{ml}$ in cow's milk. A small amount of scylloinositol was found in both human and cow's milk, while dextroinositol was not found in either.
\end{abstract}

Milk contains myoinositol, which is a vitamin of the vitamin B complex group and is an essential nutrient for the growth of some microorganisms and young animals (1-3). Myoinositol has been found in free form or in the form of inositol phospholipid in milk as well as in animal tissues $(4,5)$. The quantitative analyses of total or free myoinositol in milk have been already investigated by means of bioassay with an inositol-requiring yeast by NAGASAWA et al. (6) and other workers $(7,8)$. However, the microbiological assay requires rather complicated and laborious techniques and is easily affected by inherent factors.

Recently, the gaschromatographic method, which has some advantages over bioassay and other chemical methods, has been employed in the analyses of inositol in animal tissues (9-12). In this work, we used the gaschromatographic method for the quantitative analyses of inositol in milk and thereby showed the content of total myoinositol at different lactation periods, the content of lipidbound myoinositol, and the presence of inositol isomer in human and cow's milk.

1 小笠勝啓, 久保山盛雄, 清沢 功, 鈴木 隆, 伊藤真弓 


\section{EXPERIMENTAL}

Milk. Samples of human and cow's milk were collected for 1-51 days after parturition, frozen immediately, and stored at $-15^{\circ} \mathrm{C}$.

Chemicals. Commercial myoinositol (Wako Pure Chem. Ind. Ltd., Tokyo) was recrystallized from water and dried at $125^{\circ} \mathrm{C}$. Authentic scylloinositol was a gift of Dr. T. Tsumita, Institute of Medical Science, University of Tokyo. Dextroinositol was derived from Kasugamycin (Sanraku Ocean Co., Ltd., Tokyo). A hydrolyzate of Kasugamycin with hydrochloric acid was deionized by passing it through columns of Dowex $1 \times 2$ and Dowex $50 \mathrm{~W} \times 2$. The eluate was concentrated to dryness. The dried sample was dissolved in $50 \%$ methanol (v/v) soln. and crystallized. The crystals were recrystallized from water.

Gaschromatography. A Hitachi K53 (Hitachi, Ltd., Tokyo) with a flame ionization detector and a stainless steel column $(3 \mathrm{~mm} \times 2 \mathrm{~m})$ was used. The liquid phase for gaschromatography was a mixture of $5 \%$ Ucon LB 550X and $5 \%$ SE-30 (1.3: 2) coated on Chromosorb W HMDS (80-100 mesh). The operation conditions were as follows: column temperature, $185^{\circ} \mathrm{C}$; injection temperature, $300^{\circ} \mathrm{C}$; detector temperature, $300^{\circ} \mathrm{C}$; flow rate of carrier gas $\left(\mathrm{N}_{2}\right), 40 \mathrm{ml} / \mathrm{min}$.

Trimethylsilylation. All samples were dried on $\mathrm{P}_{2} \mathrm{O}_{5}$ in vacuo overnight before trimethylsilylation. A sample in a glass-stoppered conical tube, which contained $0.1-4.0 \mathrm{mg}$ of inositol, was dissolved in $0.5 \mathrm{ml}$ of dry pyridine stored over $\mathrm{KOH}$ pellets. Trimethylsilylimidazole (TMSI) $0.2 \mathrm{ml}$ and trimethylchlorosilane (TMCS) $0.1 \mathrm{ml}$ were added. The reaction mixture was shaken vigorously for $30 \mathrm{sec}$ and kept at $60^{\circ} \mathrm{C}$ for 2-3 min. After standing at room temperature for about $15 \mathrm{~min}, 2-5 \mu \mathrm{l}$ of the solution was injected into the gaschromatograph with a microsyringe.

Peak areas. Peak areas were determined by measuring the weights.

Preparation of samples. For the determination of the total inositol, 2-5 ml of milk was hydrolyzed with $5-10 \mathrm{ml}$ of $6 \mathrm{~N} \mathrm{HCl}$ at $120^{\circ} \mathrm{C}$ for $20 \mathrm{hr}$ in a pyrex tube sealed in vacuo. The hydrolyzate was centrifuged and filtered. The filtrate was evaporated to dryness to remove hydrochloric acid. The residue dissolved in a small amount of distilled water was deionized with Dowex $1 \times 2\left(\mathrm{OH}^{-}\right.$form, $1.8 \times 8 \mathrm{~cm})$ and Dowex $50 \mathrm{~W} \times 2\left(\mathrm{H}^{+}\right.$form, $\left.1.8 \times 5 \mathrm{~cm}\right)$. About $300 \mathrm{ml}$ of the eluate and washings was concentrated to dryness. The residue was subjected to trimethylsilylation.

For the analyses of the lipid phosphatide inositol, lipids were extracted from $40 \mathrm{ml}$ of milk by stirring with 19 vol. of chloroform-methanol $(2: 1, \mathrm{v} / \mathrm{v})$ according to the method described by Folch et al. (13). After the suspension was filtered, the filtrate was shaken with 0.2 vol. of $0.9 \% \mathrm{NaCl}(\mathrm{w} / \mathrm{v})$ soln. in the separatory funnel and left to stand overnight. The bottom layer was saved and concentrated to dryness. The residue dissolved in a small amount of chloroform was applied to silicic acid column (Wakogel C-100, Wako Pure Chem. Ind. Ltd., 
Tokyo) to obtain the fraction of the lipid phosphatide inositol. Chloroform, acetone, chloroform-methanol mixture $(1: 1, \mathrm{v} / \mathrm{v})$ and methanol were eluted through the column in order, and chloroform-methanol and methanol fraction were concentrated. The residue was taken to hydrolysis in the same way as the determination of total inositol.

The separation of scylloinositol from milk without hydrolysis was done by the method of Tsumita et al.(14). Skim milk was centrifuged at $81,000 \times g$ for $30 \mathrm{~min}$ and the supernatant was dialyzed against distilled water. After the dialyzable solution was concentrated, the residue was deionized with Dowex $1 \times 4$ $\left(\mathrm{OH}^{-}\right.$form $)$and Dowex $50 \mathrm{~W} \times 4\left(\mathrm{H}^{+}\right.$form $)$. The eluate was concentrated and adjusted to $\mathrm{pH} 9.5$ with $\mathrm{NH}_{4} \mathrm{OH}$. The solution was applied to Dowex $1 \times 2$ (borate form) column to eliminate myoinositol and lactose. The non-adsorbed fraction was concentrated to dryness and subjected to gaschromatography.

Internal standard. Triphenylmethane was used as internal standard.

\section{RESULTS AND DISCUSSION}

\section{Gaschromatogram}

The relative retention times of authentic inositol, other polyols, and triphenylmethane in this condition are shown in Table 1. Myoinositol and triphenylmethane were completely separated from each other and also from other polyols, and the peaks of disaccharides such as lactose, lactulose, and sucrose were not detected. TMS-myoinositol was stable and the ratio of peak areas of TMSmyoinositol and triphenylmethane was constant for several hours.

Table 1. The relative retention times of authentic inositol, other polyols, and triphenylmethane.

\begin{tabular}{lc}
\hline & Relative retention time \\
\hline Fructose & 0.30 \\
Galactose & $0.36,0.46$ \\
Glucose & $0.41,0.62$ \\
Dextroinositol & 0.48 \\
Scylloinositol & 0.70 \\
Myoinositol & 0.88 \\
Triphenylmethane & 1.00 \\
\hline
\end{tabular}

A gaschromatogram tracing of TMS-derivatives of human milk treated as described is shown in Fig. 1. The gaschromatograms of all samples prepared from human and cow's milk at various lactation periods showed similar patterns. The peaks corresponding to glucose and galactose which might remain as hydrolyzate of lactose in the sample were not found. They might be decomposed by hydrochloric acid and adsorbed in the resin. 


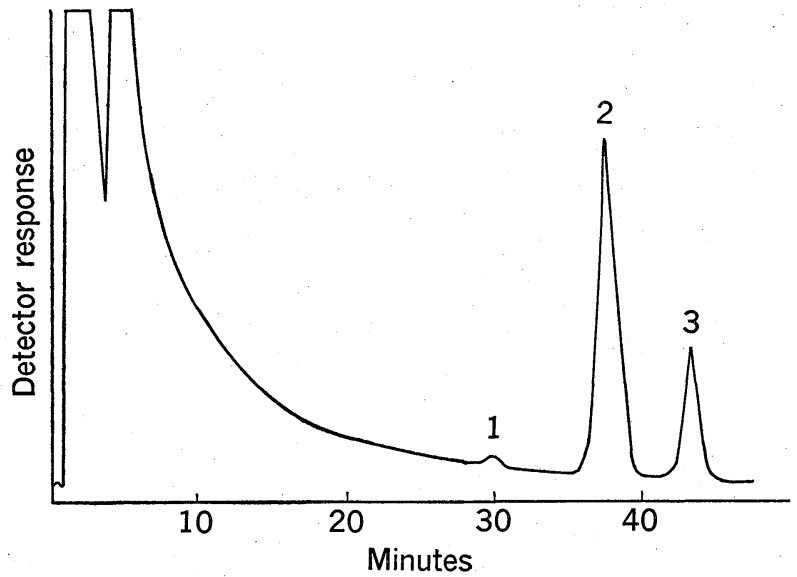

Fig. 1. A gaschromatogram of inositol extracted from human milk and triphenylmethane. 1, Scylloinositol; 2, myoinositol; 3, triphenylmethane.

Table 2. Recovery of myoinositol added to milk.

\begin{tabular}{|c|c|c|c|}
\hline \multicolumn{2}{|c|}{ Total myoinositol found $(\mu \mathrm{g})$} & \multirow{2}{*}{$\underset{(\mu \mathrm{g})}{\mathrm{a}-\mathrm{b}}$} & \multirow{2}{*}{$\begin{array}{l}\text { Recovery } \\
(\%)\end{array}$} \\
\hline $400 \underset{\text { (a) }}{\mu \mathrm{g} \text { added }}$ & $\begin{array}{l}200 \mu \mathrm{g} \text { added } \\
\text { (b) }\end{array}$ & & \\
\hline $601.3^{a}$ & $411.4^{a}$ & 189.9 & 95.0 \\
\hline
\end{tabular}

a Six samples were tested.

\section{Recovery}

For the evaluation of the procedure described above, a recovery test was carried out with two separate samples of milk to which $400 \mu \mathrm{g}$ and $200 \mu \mathrm{g}$ of myoinositol were added before hydrolysis. After each sample was treated as described, the content was measured using triphenylmethane as an internal standard. The recovery is shown in Table 2.

\section{Total myoinositol in human and cow's milk}

The content of total myoinositol in human and cow's milk at different lactation periods is shown in Fig. 2. In general, the content in human milk was about three times higher than in cow's milk. In both human and cow's milk, the colostrum content was high, then decreased rapidly, and reached nearly a constant value at the first stage of mature milk. The content of total myoinositol in human milk was $32.7 \pm 15.2 \mathrm{mg} / 100 \mathrm{ml}$ in colostrum, $17.8 \pm 1.9 \mathrm{mg} / 100 \mathrm{ml}$ in transitional milk, and $14.9 \pm 3.1 \mathrm{mg} / 100 \mathrm{ml}$ in mature milk. In cow's milk, it was $10.6 \pm 1.0,7.0 \pm 1.1$, and $4.1 \pm 1.0 \mathrm{mg} / 100 \mathrm{ml}$, respectively. In human milk, the difference of the analytical value between colostrum and transitional milk was 


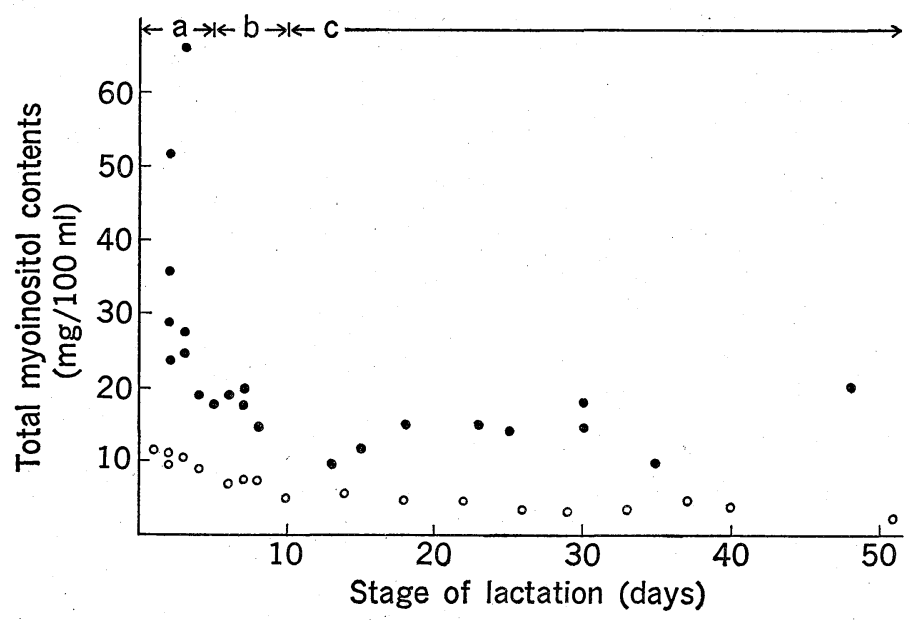

Fig. 2. Content of total myoinositol in human and cow's milk at different lactation periods. O, Human milk; cow's milk. a, Colostrum: 1-5 days after parturition; $b$, transitional milk: 6-10 days after parturition; c, mature milk: $14-51$ days after parturition.

statistically significant $(p<0.05)$, and it was also similar between transitional and mature milk $(p<0.01)$.

The significance of the high content of myoinositol in colostrum is not defined. Namely, it is not clarified that it may depend on either the simple accumulation in the breasts, or the active transport into the milk at the early stage of lactation. However, these results suggest that myoinositol may be an essential nutrient for newborn infants which grow rapidly after birth.

The wide range of standard deviation of the content in human colostrum might be due to individual differences. In cow's milk, the standard deviation was relatively small, perhaps because the tested milk was obtained from a few cows.

\section{Lipid-bound myoinositol}

For the quantitative determination of the lipid phosphatide inositol, the number of the tested samples was two of colostrum and three of mature milk in humans, and two of colostrum and two of mature milk in cows. In both

Table 3. Content of lipid-bound myoinositol in human and cow's milk.

\begin{tabular}{lccc}
\hline & $\begin{array}{c}\text { Number } \\
\text { of } \\
\text { samples }\end{array}$ & $\begin{array}{c}\text { Lipid-bound } \\
\text { myoinositol } \\
(\mathrm{mg} / 100 \mathrm{ml})\end{array}$ & $\begin{array}{c}\text { Percent of } \\
\text { total } \\
\text { myoinositol }\end{array}$ \\
\hline Human milk & 5 & $0.22 \pm 0.09$ & $1.0 \pm 0.6$ \\
Cow's milk & 4 & $0.36 \pm 0.10$ & $6.3 \pm 1.3$ \\
\hline
\end{tabular}


human and cow's milk, the difference of the content between colostrum and mature milk was not significant. In Table 3, the average of each sample of human and cow's milk is shown. It is interesting that the content of lipid-bound myoinositol was rather high in cow's milk in comparison with humans, contrary to the content of total myoinositol. It is unknown what role the lipid phosphatide inositol plays in the nutrition and physiology of the body. However, slight differences between colostrum and mature milk, and between human and cow's milk, may suggest that lipid-bound myoinositol exists as a component of the tissues and only free myoinositol has the activity as a vitamin.

No attempt was made to analyse protein-bound myoinositol.

\section{Scylloinositol and dextroinositol}

In the gaschromatograms of both human and cow's milk, one small peak different from that of myoinositol and triphenylmethane was observed (Fig. 1). The relative retention time of this peak was 0.70 and this corresponded to that of authentic scylloinositol. Therefore, it was inferred that this peak originated from scylloinositol. For the further definition, the extraction of scylloinositol from milk without hydrolysis was attempted. The gaschromatogram of the extract indicated the presence of scylloionositol. From this result, it was confirmed that milk contained scylloinositol. The precise content was uncertain because the peak areas of scylloinositol were too small to measure the weights. It was roughly estimated to be less than $1 \mathrm{mg} / 100 \mathrm{ml}$ in human colostrum and to be a trace in cow's milk. On this connection, it has been indicated by SHAW (15) that in the dolphin milk free scylloinositol accounted for $42 \%$ of myoinositol. He supposed that scylloinositol is likely to be of dietary origin in the dolphin since small cartilagenous fish which contains scylloinositol as the principal cyclitol is a logical source of food for the dolphin. Scylloinositol, however, might be formed in species-specific demand.

As for dextroinositol, the peak was not observed in the gaschromatograms of both human and cow's milk. Dextroinositol seemed not to be present in any

Table 4. Inositol content in human and cow's milk obtained by gaschromatographic and microbiological methods $(\mathrm{mg} / 100 \mathrm{ml})$.

\begin{tabular}{llcc}
\hline & & $\begin{array}{c}\text { By } \\
\text { gaschromatographic } \\
\text { method }\end{array}$ & $\begin{array}{c}\text { By } \\
\text { microbiological } \\
\text { method }\end{array}$ \\
\hline \multirow{3}{*}{ Human } & colostrum & $32.7 \pm 15.2(9)$ & $31.2 \pm 14.1(10)$ \\
& transitional milk & $17.8 \pm 1.9(4)$ & \\
& mature milk & $14.9 \pm 3.1(8)$ & $12.2 \pm 4.5(19)$ \\
\hline \multirow{3}{*}{ Cow's } & colostrum & $10.6 \pm 1.0(5)$ & $9.4 \pm 4.7(9)$ \\
& transitional milk & $7.0 \pm 1.1(4)$ & \\
& mature milk & $4.1 \pm 1.0(9)$ & $3.3 \pm 1.0(10)$ \\
\hline
\end{tabular}

( ) shows number of samples tested. 
of the milk.

Also lipid-bound scylloinositol and lipid-bound dextroinositol were not observed.

\section{Comparison with microbiological method}

Table 4 shows the content of total inositol in human and cow's milk obtained by the present method and the microbiological method as reported previously (6). Each value agrees approximately with the other. The slight increase of average values obtained by the present method may have resulted from the difference in recovery in both methods. Therefore, the present method is suitable for the quantitative analyses of inositol for precision, rapidity, and ability to separate the isomer.

We are grateful to Dr. Hamao Umezawa, Institute of Microbiological Chemistry, for supplying Kasugamycin and to Dr. Toru Tsumita, Institute of Medical Science, University of Tokyo, for the gift of scylloinositol.

Grateful acknowledgement is also due to Mr. Heihachi Inoh, the President of Morinaga Milk Industry Co., Ltd., for his interest and encouragement in the preparation of the manuscript.

\section{REFERENCES}

1) Nagasawa, T., Kiyosawa, I., Suzuki, T., and Goto, S., J. Japan. Soc. Food and Nutr., 22, 420 (1969).

2) Wells, I. C. and Hogan, J. M., J. Nutrition, 95, 55 (1969).

3) Buston, H. W. and Pramaniko, E. L., Am. J. Botany, 32, 678 (1945).

4) Morrison, W. R., Lipids, 3, 101 (1968).

5) Nakanishi, T. and KAYA, K., Japan. J. Dairy Sci., 18, A-48 (1969).

6) Nagasawa, T., Kiyosawa, I., Niyomura, M., and Toyoda, M., Japan. J. Zootech. Sci., Suppl., 40, 106 (1969).

7) Bernhard, K., Schweiz. Milchztg., 80, 125 (1954).

8) BAUMgaertel, T., Med. Ernährung, 5, 112 (1964).

9) Lee, Y. C. and Ballou, C. E., J. Chromatog., 18, 147 (1965).

10) Narumi, K., Arita, M., Kitagawa, M., Kumazawa, A., and Tsumita, T., Japan. J. Exp. Med., 39, 399 (1969).

11) Roberts, R. N., Johnston, J. A., and Fuhr, B. W., Anal. Biochem., 10, 282 (1965).

12) Wells, W. W., Pittman, T. A., and Wells, H. J., Anal. Biochem., 10, 450 (1965).

13) Folch, J., Lees, M., and Sloane Stanley, G. H., J. Biol. Chem., 226, 497 (1956).

14) Narumi, K. and Tsumita, T., Japan. J. Exp. Med., 39, 409 (1969).

15) Shaw, D. H., Carbohyd. Res., 19, 419 (1971). 